\title{
PENGARUH PENGGUNAAN SEMEN SEBAGAI BAHAN STABILISASI TANAH LUNAK DESA MATANG PANYANG TERHADAP KUAT GESER
}

\author{
Lis Ayu Widari. Said Jalalul Akbar, Hamzani, Ardiansyah Putra Bulang \\ Jurusan Teknik Sipil Universitas Malikussaleh \\ email: lisayuwidari@gmail.com, jaakidani@gmail.com, \\ hamzani.hasbi@gmail.com,dian_24syah@gmail.com
}

\begin{abstract}
Abstrak
Tanah lunak adalah tanah yang memiliki nilai daya dukung yang sangat rendah. Penelitian dilakukan terhadap tanah di desa Matang Panyang kabupaten Aceh Utara yang mempunyai nilai indeks plastisitas sebesar $20,31 \%$. Tujuan penelitian ini adalah untuk mengetahui pengaruh penambahan semen terhadap tanah lunak dankuatgeser. Penelitian terhadap pemeriksaan sifat-sifat fisis danmekanis tanah dengan penambahan semen, yaitu $0 \%, 3 \%$, $6 \%, 9 \%$ terhadap berat kering tanah. Menurut AASTHO tanah digolongkan ke dalam jenis tanah A-7-6 yaitu jenis tanah berlempung dan berdasarkan sistem klasifikasi USCS tergolong ke dalam jenis tanah lempung plastisitas rendah (CL).Kadar air optimum tanah asli (woptimum) 20\% dan kepadatan kering ( $\gamma d \max ) 1,517 \mathrm{gram} / \mathrm{cm}^{3}$. Dari hasil pengujian direct shear kuat geser maksimum terjadi pada kadar semen $9 \%$ yaitu sebesar (c) $0,70 \mathrm{~kg} / \mathrm{cm} 2$, (Ø) $49,62^{\circ}$. Sedangkan pada uji triaksial kuat geser maksimum terjadi pada kadar semen $6 \%$ yaitu sebesar (Ø) $40^{\circ}$ (c) $4,519 \mathrm{~kg} / \mathrm{cm} 2$.
\end{abstract}

Kata kunci: Semen, Direct Shear, Triaksial, Kuat Geser

\section{Pendahuluan}

Tanah merupakan material yang terdiri dari agregat (butiran) mineralmineral padat yang tidak tersementasi (terikat secara kimia) satu sama lain dan dari bahan-bahan organic yang telah melapuk (yang berpartikel padat) disertai dengan zat cair dan gas yang mengisi ruang-ruang kosong diantara partikelpartikel padat tersebut. Tanah berguna sebagai bahan bangunan pada berbagai macam pekerjaan teknik sipil, disamping itu tanah berfungsi juga sebagai pendukung pondasi dari bangunan. Di dalam pekerjaan di lapangan sering dijumpai masalah-masalah geoteknik yang berkaitan dengan tanah. Salah satu tanah yang kurang mendukung untuk pekerjaan konstruksi sipil adalah tanah lunak. Faktor-faktor yang mempengaruhi kuat geser tanah antara lain yaitu keadaan tanah, jenis tanah, kadar air, jenis beban dan tingkatnya, metode pengujian, tingkat regangan serta anisotropis

Tanah lunak adalah tanah yang memiliki daya dukung yang sangat rendah sehingga bila tanah lunak menerima beban, agregat dari perkerasan akan masuk ke dalam tanah lunak pada saat pemadatan dilaksanakan dan mengakibatkan kekuatan struktur perkerasan berkurang. Pembangunan Konstruksi di atas tanah lunak akan menghadapi beberapa masalah geoteknik salah satunya adalah timbunan badan jalan, masalah yang muncul adalah stabilitas timbunan dan 
penurunankon solidasi tanah yang apabila mengalami pembebanan di atasnya maka tekanan air poriakan naik sehingga air pori keluar dan menyebabkan berkurangnya volume tanah, oleh karena itu akan terjadi penurunan pada tanah. Dilihat dari fakta di atas maka diperlukan perlakuan khusus terhadap tanah lunak yang mempunyai daya dukung rendah. Stabilisasi tanah adalah hal yang sangat penting bagi pembangunan suatu konstruksi apabila tanah yang digunakan tersebut memiliki karakteristik yang kurangbaik, seperti tanah lunak

\section{Tinjauan Kepustakaan}

\subsection{Tanah}

Tanah merupakan semua endapan alam yang berhubungan dengan teknik sipil,kecuali batuan tetap. Batuan tetap menjadi ilmu tersendiri yaitu mekanika batuan (rock mechanics). Endapan alam tersebut mencakup semua bahan, dari tanah lempung (clay) sampai berangkal (broulder). Tanah dapat didefenisikan untuk maksud teknis Padat (solid)".

\subsection{Klasifikasi Tanah}

Sistem klasifikasi tanah adalah suatu system pengaturan beberapa jenis tanahyang berbeda-beda tapi mempunyai sifat yang serupa ke dalam kelompokkelompok dan subkelompok-subkelompok berdasarkan pemakaiannya. Pada umumnya tanah diklasifikasikan sebagai tanah yang kohesif dan tidak kohesif atau sebagai tanah yang berbutir kasar dan halus. Klasifikasi tanah sangat membantu perencana dalam memberikan pengarahan melalui cara empiris yang tersedia dari hasil pengalaman yang lalu. Maka dari itu metode yang akan digunakan pada penelitian ini adalah system klasifikasi American association of state highway and transportation Official (AASHTO).

Sistemklasifikasi tanah (AASHTO), menurut BrajaM.Das (1995),system ini dikembangkan pada tahun 1929 sebagai Public Road Administrator System.Pada sistem ini, tanah diklasifikasikan ke dalam tujuh kelompok besar,yaitu A-1 sampai dengan A-7. Tanahyang diklasifikasikan ke dalam A-1, A-2, danA-3 adalah tanah berbutir di mana $35 \%$ atau kurang dari jumlah butiran tanah tersebut lolos ayakan No 200. Tanah yang lebih dari 35\% butiran lolos ayakan No.200 diklasifikasikan kedalam kelompok A-4, A-5 ,A-6, dan A-7. Butiran dalam kelompok A-4 sampai dengan A-7 tersebut sebagian besar adalah lanau dan lempung

\subsection{PemadatanTanah}

Pada dasarnya pemadatan tanah merupakan usaha untuk mempertinggi Kepadatan tanah dengan pemakain energi mekanis untuk menghasilkan pemampatan partikel.tanah dapat dikerjakan pada mulanya dengan pengeringan, penambahan air, agregat (butir-butir) tersebut dengan bahan-bahan stabilisasi sepertisemen Portland(PC),gamping, abu batu bara atau bahan lainnya. Tujuan pemadatan ialah untuk memperbaiki sifat-sifat teknis massa tanah, yaitu:

1. Menaikkan kekuatannya.

2. Memperkecil pemampatan dan daya rembes airnya.

3. Memperkecil pengaruh air terhadapnya. 


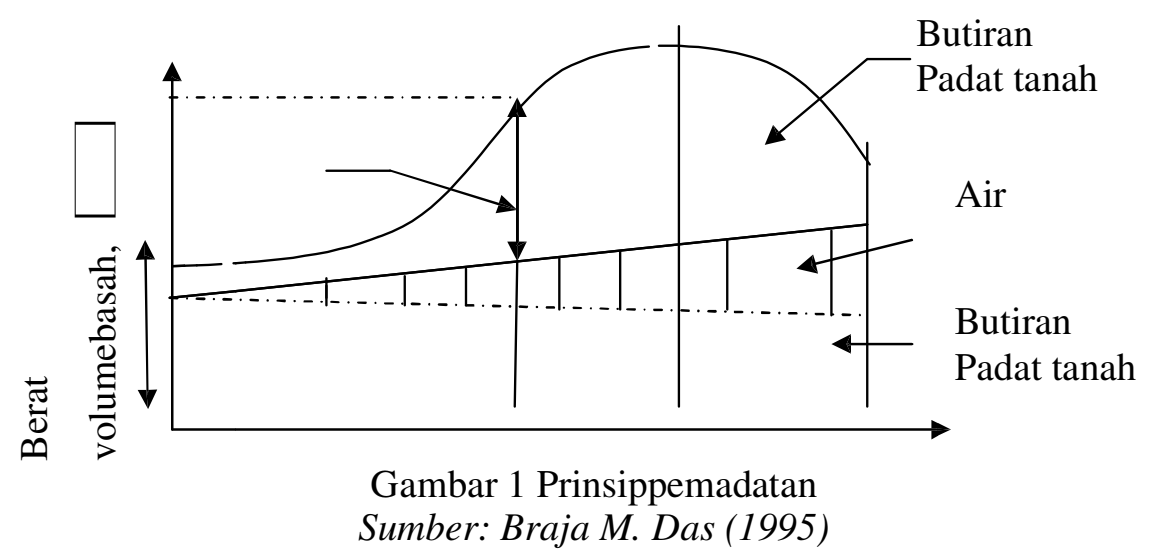

Kerugian pertama adalah pemuaian (bertambah kadar air dari nilai patokannya) dan kemungkinan pembekuan tanah itu akan membesar. Proktor mendefinisikan empat variabel pemadatan tanah,yaitu:

1. Usahapemadatan (energipemadatan)

2. Jenis tanah

3. Kadarair

4. Berat isi kering(proktormenggunakan angkapori)

Apabila diketahui tanah basah di dalam cetakan yang volumenya diketahui, maka berat isi basah dapat langsung dihitung dengan persamaan 1

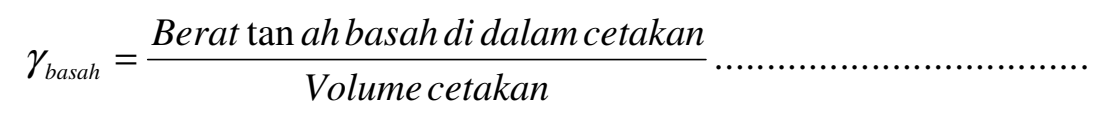

Dari uji pemadatan dapat diketahui derajat kepadatan tanah yang diukur diukur dari berat volume keringnya. Hubungan berat volume kering $(\gamma \mathrm{d})$ dengan berat volume basah $(\gamma b)$ dan kadar air $(\mathrm{w})$ dinyatakan dengan persamaan 2 :

$$
\gamma=\frac{\gamma_{b}}{1+w}
$$

di mana:

$$
\begin{aligned}
& \gamma \mathrm{b}=\text { berat volume tanah basah }\left(\mathrm{gr} / \mathrm{cm}^{3}\right) \\
& \gamma \mathrm{d}=\text { berat volume tanah kering }\left(\mathrm{gr} / \mathrm{cm}^{3}\right) \\
& \mathrm{w}=\operatorname{kadar} \text { air }(\%)
\end{aligned}
$$

Setelah dilakukan pemadatan kerapatan butiran dan kadar air tanah juga kerapatan keringnya ditentukan.Prosesini diulangi sedikitnya lima kali untuk tanah yang sama, dan kadar air contoh tanah tersebut dinaikkan pada setiap proses.Untuk suatu kadar air tertentu berat volume kering maksimum secara teoritis didapat bila pori-pori tanah sudah tidak ada udara lagi,yaitu pada saat di mana derajad kejenuhan tanah sama dengan $100 \%$. Jadi berat volume kering maksimum (teoritis) pada suatu kadar air tertentu dengan kondisi zero air voids (pori-pori tanah tidak mengandung udara sama sekali) dapat di tulis sebagai: 


$$
\gamma_{z a v}=\frac{G s . \not w}{1+e}
$$

di mana:

$$
\begin{aligned}
& \gamma \mathrm{zav}=\text { berat volume pada kondisi zero air void } \\
& \gamma \mathrm{w}=\text { berat volume air } \\
& \mathrm{e} \quad=\text { Angka pori } \\
& \text { Gs }=\text { berat spesifik butiran padat tanah }
\end{aligned}
$$

\subsection{Kuat GeserTanah}

Kuat geser atau tepatnya ketahanan geser ini perlu diketahui untuk analisis stabilitas tanah. Menurut Braja M.Das (1985), kekuatan geser suatu massa tanah merupakan perlawanan internal tanah tersebut persatuan luas terhadap keruntuhan atau pergeseran sepanjang bidang geser dalam tanah yang dimaksud. Untuk menganalisis masalah stabilitas tanah seperti daya dukung stabilitas talud (lereng), dan tekanan tanah ke samping pada turap maupun tembok penahan tanah,mulamula kita harus mengetahui sifat-sifat ketahanan penggesernya tanah tersebut. Untuksebagian besarmasalah-masalah mekanika tanah, garis tersebut cukup didekati dengan sebuah garis lurus yang menunjukkan antara tegangan normal dan geser (Coulomb, 1776)

$$
t_{f}=c+\sigma \tan \phi
$$

di mana:

$$
\begin{aligned}
& t_{f}=\text { tekanan geser pada bidang runtuh } \\
& c=\text { kohesi } \\
& \sigma=\text { tekanan efektif } \\
& \varphi=\text { sudut geser dalam }
\end{aligned}
$$

Hubungan di atas disebut juga sebagai kriteria keruntuhan Mohr-Coulomb. Pada tanah jenuh air, besar tegangan normal total pada sebuah titik adalah sama dengan jumlah teganganefektifnyaditambah dengan tegangan air pori, atau:

$$
c=\sigma^{\prime}+u
$$

Tegangan efektif $\sigma^{\prime}$ diterima oleh bagian butiran padat dari tanah. Jadi berdasarkan prinsip mekanika tanah, persamaan dapat ditulis menjadi:

$$
\begin{aligned}
& t_{f}=c+(\sigma-u) \tan \phi \\
& t_{f}=c+\sigma^{\prime} \tan \phi
\end{aligned}
$$

\subsection{PengujianTriaksial UU}

Uji geser triaksial adalah uji yang paling dapat diandalkan untuk menentukan parameter tegangan geser. Bila sampel tanah lempung dikonsolidasi pada tegangan sel sebesar $\sigma_{3}$ dan kemudian ditekan (geser) sampai 
mencapai keruntuhan tanpa mengizinkan adanya pengaliran air dari dan ke dalam benda uji, kondisi tegangan total pada saat runtuh dapat digambarkan dengan lingkaran Mohr $P$ pada gambar 2. Karena kekuatan geser kondisi air termampatkan dari tanah tidak tergantung pada tegangan penyekap maka persamaan kuat geser dapat dinyatakan dalam persamaan 7 sebagai berikut:

$$
t=\frac{\sigma_{1}}{f_{2}}=\frac{q u}{2}=c
$$

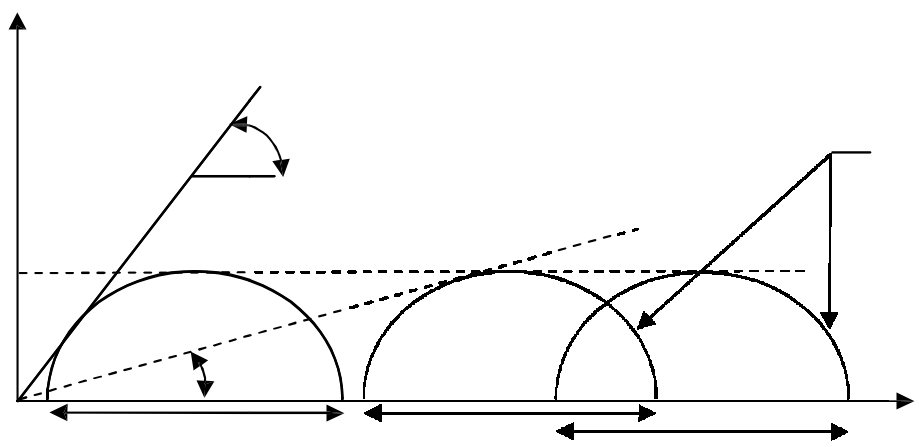

Gambar 2 LingkaranMohr untuk tegangan total padasaat runtuh Sumber: Braja M. Das (1985)

\subsection{PengujianDirect Shear}

Kekuatangeser tanah (SoilshearSterngth) dapat didefinisikan sebagai kemampuan maksimum tanah untuk bertahan terhadap usaha perubahan bentuk pada kondisi tekanan (Pressure) dan kelembapan tertentu. Dun et al (1980) mengatakan bahwa jika kekuatan tanah lebih besar dari pada tegangan yang bekerja pada tanah maka tanah aman terhadap keruntuhan pada bidang yang ditinjau, tetapi jika tegangan tersebut lebih kekuatan tanah maka akan terjadi keruntuhan.

Pengujian kuat geser tanah dengan alat Directshear dilaksanakan dengan menggunakan sebuah kotak geser. Sebuah sampel tanah ditempatkan dalam kotak geser langsung dan diberi beban normal $(\mathrm{N})$, kemudian diberi gaya horizontal (T) untuk menggeser sampel sepanjang bidang horizontal A-A. alat uji tersebut terdiri dari sebuah kotak logam berisi sampel tanah yang akan diuji. Kotak tersebut terbagidua sama sisi dalam arah horizontal. Gaya normal pada sampel tanah didapat dengan menaruh suatu beban di atas sampel tanah tersebut. Beban dapat menyebabkan tekanan pada sampel tanah tersebut.Gaya geser diberikan dengan mendorong sisi kotak sebelah atas sampai terjadi keruntuhan geser pada tanah. Pada tanah kohesif sudut geser $\theta$ merupakan parameter yang mempunyai peranan utama dalam menentukan daya dukung tanah (Bearing Capacity). Selama pengujian kuat geser langsung dicatat harga dial horizontal, harga dial vertical dan provingring. Ketiga harga tersebut digunakan dalam perhitungan dengan memakai persamaan:

Pengaruh Penggunaan Semen Sebagai Bahan Stabilisasi Tanah Lunak Desa Matang Panyang Terhadap Kuat Geser - Lis Ayu Widari. Said Jalalul Akbar, Hamzani, 


$$
\begin{aligned}
& \% d=h \arg \text { a dial horizontal } x \frac{0,01}{d \text { cutting ring } \times 10} \times 100 \% \\
& \% d=h \arg \text { a dial vertikal } x \frac{0,01}{d \text { cutting ring } \times 10} \times 100 \% \ldots \ldots \\
& \text { Cor Area }=\frac{\text { luas cutting ring }}{100 /(100-\% d)} \\
& \text { Tegangan geser }=\frac{h \arg a \text { proving ring }}{\text { correctionarea }}
\end{aligned}
$$

Jika hubungan antara tegangan normal dan tegangan geser yang berupa sejumlah titik yang masing-masing dihubungkan,maka terbentuk garis lurus yang disebut garis kekuatan (Strength Line). Sudut yang dibentuk antara garis horizontal dengan garis kekuatan disebut sudut geser dalam $(\theta)$. Nilai kohesi (c) adalah angka yang vertical.

\section{Metode Penelitian}

Untuk mendapatkan data yang dibutuhkan dalam penelitian ini, dilakukan beberapa tahap pemeriksaan dan pengujian yang berkaitan antara satu dengan lainnya.Data yang diperlukan meliputi data primer dan data sekunder, data primer adalah data utama dalam penelitian yang diperoleh dari hasil pengamatan atau pemeriksaan terhadap benda uji seperti kadar air, berat jenis, batas cair, batas plastis, analisa saringan, alat uji standar proctor. Data sekunder adalah data pendukung data primer yang diperlukan dalam penelitian seperti angka koreksi benda uji, studi literature dengan persiapan dan pengadaan material yaitu tanah asli dan bahan penambahan yaitu semen.

\section{Hasil dan Pembahasan}

\subsection{Pengujian laboratorium}

Tanah yang berasal dari Desa Matang Panyang Kecamatan Baktiya Barat Kabupaten Aceh utara mengandung kadar air sebesar 22,915\%, Berat volume tanah rata-rata1,632 gram $/ \mathrm{cm}^{3}$, Berat jenis tanah rata-rata $2.586 \mathrm{gram} / \mathrm{cm}^{3}$.

\subsection{Sistem klasifikasi tanah}

Berdasarkan system klasifikasi AASTHO maka tanah dari Desa Matang Panyang Kecamatan Baktiya Barat Kabupaten Aceh utara dapat klasifikasikan kedalam kelompok tanah berlempung A-7-6.

\subsection{Pengujian pemadatan (proctor test)}

Dari nilai density ( $\gamma \mathrm{dmax}) 1,51 \mathrm{gram} / \mathrm{cm}^{3}$, maka untuk tanah asli diperoleh nilai kadar air optimum ( 


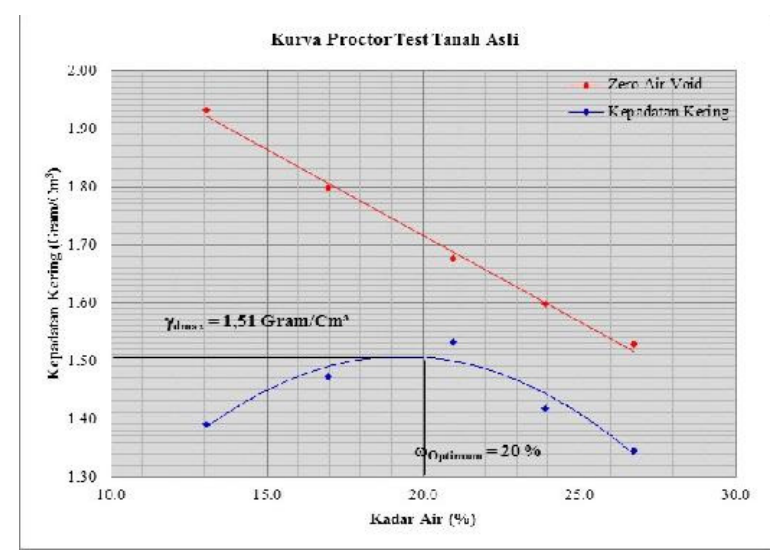

Gambar 3 Grafik Pemadatan Tanah Asli

\subsection{PengujianTriaksial Laboratorium}

Pada pengujian Triaksial penambahan semen dengan variasi $0 \%$ tanah asli, $3 \%$ semen, $6 \%$ semen, 9\% semen. Kadar airyang dipakai untuk pengujian ini diperoleh dari kadar air optimum (Wopt) yang didapat dari hasil pengujian proctor. Dengan benda uji 3 sampel, sampel I diberikan $\sigma 3=0,5 \mathrm{~kg} / \mathrm{cm}^{2}$, sampel II $\sigma 3=1 \mathrm{~kg} / \mathrm{cm}^{2}$, sampel III $\sigma 3=1,5 \mathrm{~kg} / \mathrm{cm}^{2}$. Jadi benda uji keseluruhannya dalam pengujian Triaksial ada 12 sampel benda uji.Uji Triaksial yang digunakan yaitu tipe Unconsolidated-Undrained (UU).

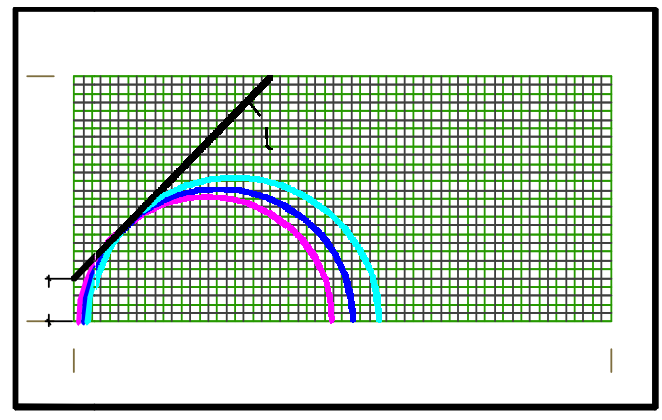

Gambar 4 Grafik Lingkaran Mohr Clay Tanah Asli

Dari gambar 4 didapat $\square=47 \square, \mathrm{c}=4,882 \mathrm{~kg} / \mathrm{cm}^{2}$ dengan $\square 3=0,5 \mathrm{~kg} / \mathrm{cm}^{2}$ hasil dari pengujian didapat $\square 1=28,53 \mathrm{~kg} / \mathrm{cm}^{2}, \square 3=1 \mathrm{~kg} / \mathrm{cm}^{2}$ hasil dari pengujian didapat $\square 1=30,37 \mathrm{~kg} / \mathrm{cm}^{2}, \square 3=1,5 \mathrm{~kg} / \mathrm{cm}^{2}$ hasil dari pengujian didapat $\square 1=32,87$ $\mathrm{kg} / \mathrm{cm}^{2}$.

\subsection{PengujianDirectShear}

Pada pengujian direct shear terhadap tanah asli dan dengan variasi semen dengan stabilisasi, 3\%, 6\%, dan 9\% dengan masa pemeraman 24 jam. Kadar air yang dipakai untuk pengujian ini diperoleh dari kadar air optimum (Wopt) yang didapat dari hasil pengujian proctor test. Dengan benda uji 3 sampel dalam satu 
variasi, sampel I diberikan beban $=3 \mathrm{~kg}$, sampel II $=5 \mathrm{~kg}$, sampel III $=8 \mathrm{~kg}$. Jadi benda uji keseluruhannya dalam pengujiandirect shear ada12 sampel benda uji.

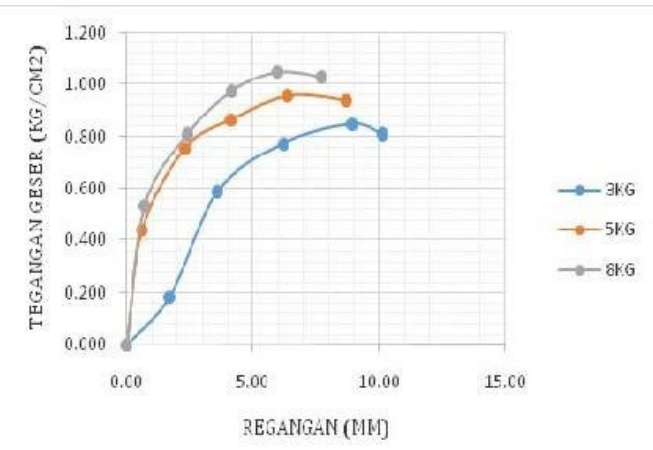

Gambar 5 Grafik Hubungan Tegangan Geser Dengan Regangan Pada Tanah Asli

Tabel 1 Hasil KeseluruhanPengujianDirect Shear

\begin{tabular}{|c|c|c|c|c|c|c|c|}
\hline No & $\begin{array}{c}\text { Penambahan } \\
\text { Kapur }(\%)\end{array}$ & $\begin{array}{c}\sigma 1 \\
\left(\mathrm{~kg} / \mathrm{cm}^{2}\right)\end{array}$ & $\begin{array}{c}\sigma 2 \\
\left(\mathrm{~kg} / \mathrm{cm}^{2}\right)\end{array}$ & $\begin{array}{c}\sigma 2 \\
\left(\mathrm{~kg} / \mathrm{cm}^{2}\right)\end{array}$ & $\begin{array}{c}\mathrm{C} \\
\left(\mathrm{kg} / \mathrm{cm}^{2}\right)\end{array}$ & $\begin{array}{c}\Phi \\
\left(^{\circ}\right)\end{array}$ & $\begin{array}{c}\sigma_{f} \\
\left(\mathrm{~kg} / \mathrm{cm}^{2}\right)\end{array}$ \\
\hline 1 & Tanah asli & 0,0962 & 0,1604 & 0,25661 & 0,750 & 53,13 & 0,7013 \\
\hline 2 & $\begin{array}{c}\text { Tanah asli }+ \\
3 \% \text { semen }\end{array}$ & 0,0962 & 0,1604 & 0,25661 & 0,650 & 67,74 & 0,2822 \\
\hline 3 & $\begin{array}{c}\text { Tanah asli }+ \\
6 \% \text { semen }\end{array}$ & 0,0962 & 0,1604 & 0,25661 & 1,050 & 42,39 & 12,087 \\
\hline 4 & $\begin{array}{c}\text { Tanah asli }+ \\
9 \% \text { semen }\end{array}$ & 0,0962 & 0,1604 & 0,25661 & 0,700 & 49,62 & 0,572 \\
\hline
\end{tabular}

Tabel 2 Hasil KeseluruhanPengujianTriaksial

\begin{tabular}{|c|c|c|c|c|c|}
\hline $\mathrm{No}$ & $\begin{array}{c}\text { Penambahan } \\
\text { Semen (\%) }\end{array}$ & $\begin{array}{c}\sigma 3 \\
\mathrm{~kg} / \mathrm{cm}^{2}\end{array}$ & $\begin{array}{c}\sigma l \\
\mathrm{~kg} / \mathrm{cm}^{2}\end{array}$ & $\underset{\left({ }^{\circ}\right)}{\Phi}$ & $\begin{array}{c}C \\
\left(\mathrm{~kg} / \mathrm{cm}^{2}\right)\end{array}$ \\
\hline \multirow[b]{3}{*}{1} & \multirow[b]{3}{*}{ Tanah asli } & 0,5 & 28,53 & \multirow[b]{3}{*}{47} & \multirow[b]{3}{*}{4,882} \\
\hline & & 1 & 30,37 & & \\
\hline & & 1,5 & 31,37 & & \\
\hline \multirow[b]{3}{*}{2} & \multirow{3}{*}{$\begin{array}{c}\text { Tanah asli }+ \\
\text { 3\%semen }\end{array}$} & 0,5 & 22,20 & \multirow[b]{3}{*}{42} & \multirow[b]{3}{*}{4,375} \\
\hline & & 1 & 23,96 & & \\
\hline & & 1,5 & 26,07 & & \\
\hline \multirow[b]{3}{*}{3} & \multirow{3}{*}{$\begin{array}{c}\text { Tanah asli }+ \\
6 \% \text { semen }\end{array}$} & 0,5 & 25,18 & \multirow[b]{3}{*}{40} & \multirow[b]{3}{*}{4,519} \\
\hline & & 1 & 26,14 & & \\
\hline & & 1,5 & 29,31 & & \\
\hline \multirow[b]{3}{*}{4} & \multirow{3}{*}{$\begin{array}{c}\text { Tanah asli + } \\
9 \% \text { semen }\end{array}$} & 0,5 & 9,85 & \multirow[b]{3}{*}{36} & \multirow[b]{3}{*}{1,987} \\
\hline & & 1 & 10,51 & & \\
\hline & & 1,5 & 10,87 & & \\
\hline
\end{tabular}




\section{Kesimpulan}

Dari hasil penelitian dan pembahasan dapat diambil beberapa kesimpulan sebagai berikut :

1. Menurut klasikasi AASHTO,tanah ini diklasifikasikan dalam kelompok A-7-6 dengan nilai group indeks (GI) sebesar 17\%. Sedangkan menurut klasifikasi USCS tanah ini termasuk ke dalam kelompok CL yaitu lempung plastisitas rendah.

2. Kadar air tanah asli yaitu22,019\%, spesifik grafity (Gs) 2,59, berat volume 2,006gr/cm3, batascair (LL) 44,10\%, batasplastis (PL) 23,79\%, dan indeks plastis (IP) $20,31 \%$.

3. Setelah melakukan uji pemadatan dapat disimpulkan bahwa pengaruh penambahan semen dengan variasi 3\%, 6\% dan 9\% dapat meningkatan kepadatan kering ( $\gamma d \max )$ dan menurunkan kadar air optimum ( hal ini disebabkan oleh adanya air yang semula mengisi pori-pori pada tanah diganti dengan bahan campuran semen, sehingga menyebabkan terjadinya pengecilan rongga-rongga antara partikel tanah.

4. Pada pengujian triaxial dan direct shear tanah asli dan penambahan $3 \%, 6 \%$ dan $9 \%$ semen menunjukkan nilai sudut geser cenderung mengecil dan nilai kohesinya cenderung meningkat. Maka semakin besar nilai parameter kuat geser tanah dikarenakan terjadinya pergeseran partikel antara tanah.

5. Kuat geser tanah asli pada tekanan air $\sigma 3$ sebesar $0,5 \mathrm{~kg} / \mathrm{cm}^{2}$ dan $\sigma 1$ sebesar $28,53 \mathrm{~kg} / \mathrm{cm}^{2}$ maka nilai kuat geser tanah yaitu $\tau \mathrm{f}$ sebesar $0,7013 \mathrm{~kg} / \mathrm{cm}^{2}$, pada tekanan air $\sigma 3$ sebesar $1 \mathrm{~kg} / \mathrm{cm}^{2}$ dan $\sigma 1$ sebesar $30,37 \mathrm{~kg} / \mathrm{cm}^{2}$ maka nilai kuat geser tanah yaitu $\tau$ f sebesar $0,2822 \mathrm{~kg} / \mathrm{cm}^{2}$, pada tekanan air $\sigma 3$ sebesar 1,5 $\mathrm{kg} / \mathrm{cm}^{2}$ dan $\sigma 1$ sebesar $31,37 \mathrm{~kg} / \mathrm{cm}^{2}$ maka nilai kuat geser tanah yaitu $\tau \mathrm{f}$ sebesar $12,087 \mathrm{~kg} / \mathrm{cm}^{2}$.

\section{Daftar Kepustakaan}

Bowles. E. Joseph, 1993, Sifat-Sifat Fisis dan Geoteknis Tanah, Terjemahan Ir Johan Kelana PutraHanum, Erlangga, Jakarta.

Braja M. Das, 1993, Prinsip-prinsip Rekayasa Geoteknis, terjemahan Ir. Johan Kelana Putra Hanum, Jilid I, Erlangga, Jakarta.

Braja M. Das, 1996, Prinsip-prinsip Rekayasa Geoteknis, terjemahan Ir. Johan Kelana Putra Hanum, Jilid II, Erlangga, Jakarta.

Dunn, et.al, 1980, Dasar-dasar Analisis Geoteknik, terjemahan Ahmad Toekiman, IKIP SemarangPress, Semarang.

Hardiyatmo, H.C, 1992, MekanikaTanah I, PT. Gramedia Pustaka Utama, Jakarta.

Wesley,L.D,1977, Mekanika Tanah, Cetakan ke enam, Pekerjaan Umum. Jakarta Selatan

Pengaruh Penggunaan Semen Sebagai Bahan Stabilisasi Tanah Lunak Desa Matang Panyang Terhadap Kuat Geser - Lis Ayu Widari. Said Jalalul Akbar, Hamzani, Ardiansyah Putra Bulang 